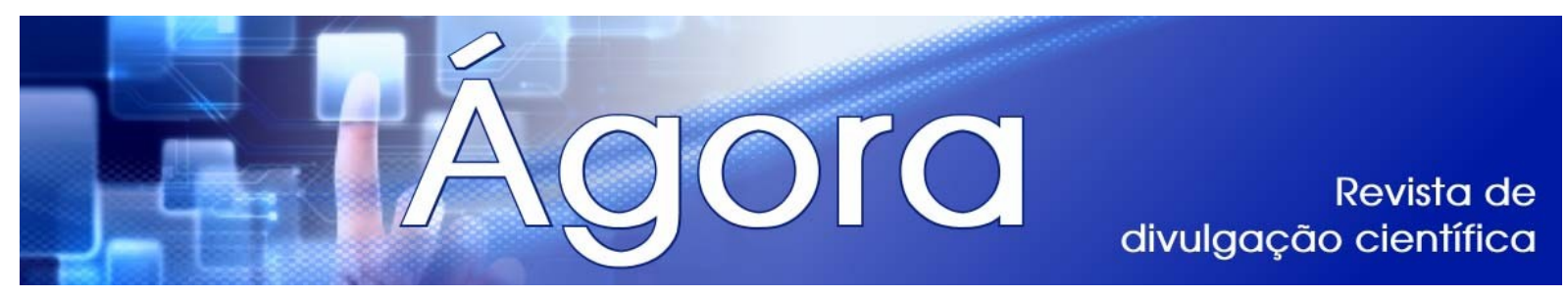

\title{
ESTUDO SOBRE A PERCEPÇÃO DO IMPACTO DO SISTEMA COOPERATIVO DE AGRICULTURA FAMILIAR NOS MUNICÍPIOS DE MAFRA, PAPANDUVA, E MONTE CASTELO
}

\author{
Clarissa Fernandes Diniz ${ }^{1}$ \\ Andreia Luciana Rosa Scharmach ${ }^{2}$
}

\begin{abstract}
RESUMO: A importância da agricultura familiar para o país vem sendo objeto de estudo e discussões tanto na esfera acadêmica como em movimentos sociais e governamentais. No estado de Santa Catarina estima- se que a agricultura familiar representa um universo de 180 mil famílias, ou seja, mais de $90 \%$ da população rural, sendo responsável por mais de $70 \%$ do valor da produção agrícola e pesqueira do estado. Inúmeros produtores estão buscando o associativismo como uma maneira de fortalecer a agricultura familiar e a pequena propriedade. Este estudo tem como objetivo examinar, através da aplicação de questionários junto aos associados de cooperativas de agricultura familiar do planalto norte catarinense, a percepção do impacto do sistema cooperativo e a relação entre o produtor e a cooperativa. Através da pesquisa de campo, evidenciou- se que a cooperativa possui um papel importante na agricultura familiar, pois para o produtor ela é uma segurança de que sua produção será comercializada e vendida por um preço melhor se comparado à venda individual. Outro aspecto constatado, é que a cooperativa está atendendo as expectativas dos associados, através da melhoria de sua renda e do trabalho diário.
\end{abstract}

Palavras- chave: Agricultura familiar. Cooperativa. Propriedade.

ABSTRACT: The importance of family agriculture for the country has been the subject of study and discussions in the academic sphere as in social movements and governmental. In the state of Santa Catarina, there estimated that family agriculture represents a universe of 180,000 families, more $90 \%$ of rural population has been responsibility for the $70 \%$ value of agricultural production and fisheries in the state. Many producers are searching the associations for fortify the family agriculture and the small property. This study objectifies to examine, through an application of questionnaires in the associated of a family agriculture cooperative of the north plateau catarinense, the perception of impacts brought for the associated's property and the relationship between a producer and cooperative. Through a field research, it was evidenced that the cooperative has an important function in the family agriculture, for the producer, it's a security that your production will be negotiated and sold for a better cost if compared a individual sale. Other aspect, is that the cooperative is satisfying the associated's expectations, through increase your income and improving the diary work.

Key Words: Family agriculture. Cooperative. Property. 


\section{INTRODUÇÃO}

A importância da agricultura familiar para o país vem recebendo destaque no cenário nacional, sendo objeto de estudo e discussões tanto na esfera acadêmica como em movimentos sociais e governamentais. Com cerca de 4,5 milhões de estabelecimentos, o segmento detêm $20 \%$ das terras e responde por $30 \%$ da produção global. Alimentos básicos que fazem parte da dieta do brasileiro como o feijão, arroz, milho, hortaliças, mandioca e pequenos animais, o setor chega a ser responsável por 60\% da produção (PORTUGAL, 2011).

Diante da importância da agricultura familiar para o país, o governo brasileiro vem aumentando seus investimentos através de programas como o Pronaf (Programa Nacional de Fortalecimento da Agricultura Familiar) e o PAA (Programa de Aquisição de Alimentos). Segundo dados do Ministério do Desenvolvimento Agrário (2011), no período de 2006 a 2007 foi disponibilizado aos agricultores para financiamento, através do Pronaf, um montante de 10 bilhões de reais. Já o PAA contribui para a formação de estoques estratégicos e para o abastecimento de mercado institucional de alimentos através das compras governamentais de gêneros alimentícios para fins diversos, permitindo aos agricultores familiares que estoquem seus produtos para serem comercializados a preços mais justos (MINISTÉRIO DO DESENVOLVIMENTO SOCIAL E COMBATE À FOME, 2011). A implementação do PAA no planalto norte catarinense remonta à segunda metade dos anos 1990, com a implantação do Banco Nacional da Agricultura Familiar (BNAF) em 1997 (ANDRADE JÚNIOR, 2009).

Todavia, apesar dos investimentos do governo federal para o desenvolvimento da agricultura familiar, os desafios enfrentados pelo sistema cooperativista são inúmeros. Para Andrade Júnior (2009) ambiente competitivo, dificuldade na gestão, conflitos interpessoais e falta de informação são alguns deles.

O impacto trazido pelo sistema cooperativista a uma propriedade de agricultura familiar é uma problemática que precisa ser estudada constantemente para que possíveis falhas que travem o desenvolvimento de seus associados sejam corrigidas.

Em Santa Catarina é evidente a transformação estrutural do espaço rural. Entre alguns pontos mais visíveis estão à concentração da produção, a redução do 
número de produtores de várias cadeias produtivas, a redução da população rural, a redução do número de jovens na agricultura, e a dificuldade de sucessão nas propriedades rurais da agricultura familiar (SILVESTRO et al., 2001; ALTMANN et al., 2008; MARCONDES, 2010; MATTEI, 2010).

Com base nos critérios de classificação do Programa Nacional da Agricultura Familiar (Pronaf), estima- se que a agricultura familiar em Santa Catarina representa um universo de 180 mil famílias, ou seja, mais de $90 \%$ da população rural. Estas famílias de agricultores, apesar de ocuparem apenas $41 \%$ da área dos estabelecimentos agrícolas, são responsáveis por mais de $70 \%$ do valor da produção agrícola e pesqueira do estado, destacando-se na produção de $67 \%$ do feijão, $70 \%$ do milho, $80 \%$ dos suínos e aves, $83 \%$ do leite e $91 \%$ da cebola (SANTA CATARINA. CARACTERÍSTICAS E POTENCIAIS, 2012).

Diante da situação exposta, o presente estudo tem por objetivo verificar a percepção do impacto do sistema cooperativo daqueles que optaram pela associação em cooperativa de agricultura familiar nos municípios de Mafra, Papanduva e Monte Castelo situados no planalto norte de Santa Catarina, identificando o perfil do associado, suas motivações e contribuições trazidas pelo sistema cooperativo para a propriedade.

O trabalho demonstra a importância das cooperativas de agricultura familiar para o país e busca evidenciar sua contribuição para determinados municípios de Santa Catarina.

\section{COOPERATIVISMO E AGRICULTURA FAMILIAR}

O cooperativismo atualmente está seguindo duas análises distintas. A primeira, de caráter ideológico, divulga os ideais da união e da solidariedade. A segunda assume uma postura crítica, comparando as cooperativas a qualquer empresa capitalista que objetiva o lucro (MARSCHALL, 2009).

Para Zylbersztajn (1994), a cooperativa assume importante papel para o desenvolvimento de seus associados, principalmente na redução dos custos por meio do poder de barganha na comercialização de insumos e a redução de riscos que estão associados a ações conjuntas. 
A característica fundiária dos produtores familiares impõe a necessidade da busca por alternativas de produção que sejam compatíveis com a disponibilidade de espaço, recurso e capacitação da mão de obra. Uma das formas de valorização da produção é através da comercialização dos produtos que destacam as características sociais da agricultura familiar e também a agroindustrialização dos produtos advindos das propriedades (MARSCHALL, 2009).

A agricultura familiar no Brasil surge como fruto de um processo histórico das políticas públicas para a agricultura, sobretudo àquelas praticadas nas décadas de 1960 a 1980 (ANDRADE JÚNIOR, 2009).

Buainain (1999) identificou cinco fases das políticas agrícolas brasileiras. A primeira fase, que data do início da década de 60 até o final da década de 70 , caracteriza-se pela montagem do Sistema Nacional de Planificação Agropecuária e criação do Sistema Nacional de Crédito Rural (SNCR), que ofertava crédito aos agricultores de maneira abundante e barata. O sistema propiciou a expansão da utilização de equipamentos agrícolas, uso de defensivos agrícolas e outras tecnologias consideradas inovadoras, além de ações na área de pesquisa e fomento e política de preços mínimos. A segunda fase, que ocorreu nos primeiros anos da década de 80 , foi marcada pelo crescente desequilíbrio externo e o agravamento da crise da dívida, retraindo e contendo o crédito agrícola. A terceira fase corresponde ao período de 1985 até 1988, assinalando o lançamento de planos econômicos que tinham como objetivos a baixa da inflação e o controle da dívida externa, além da diminuição da participação do Estado no financiamento agrícola. É neste período que há a ascensão dos movimentos sociais no campo. A quarta fase, que vai do fim dos anos 80 até 1995, foi marcada pelo neoliberalismo e diminuição da participação do Estado, surgimento do Mercosul com impactos relevantes sobre a agricultura e crescimento dos movimentos sociais no campo. No governo de Fernando Henrique Cardoso, período que corresponde a $5^{\circ}$ fase, o crédito agrícola mostra-se discriminatório por produto, por região e por produtor.

Após todo esse histórico de ações, o reconhecimento da agricultura familiar acontece através da implantação do PRONAF. O estabelecimento de políticas compensatórias acaba por incluir um contingente expressivo da população rural e atualmente as cooperativas de agricultura familiar estão voltadas para a problemática da segurança familiar (novas relações entre agricultores e 
consumidores) e sustentabilidade ambiental, onde se encontram práticas agroecológicas e recursos energéticos alternativos (ANDRADE JÚNIOR, 2009).

\section{MATERIAIS E MÉTODOS}

Para compreender a cooperativa como ferramenta de fortalecimento da agricultura familiar, buscou-se, através de uma pesquisa de campo com a utilização de questionários, identificar a visão e opiniões dos proprietários acerca da cooperativa, perfil destes e impactos trazidos para a propriedade após essa associação.

Também a pesquisa de campo foi utilizada para identificar as principais motivações e expectativas dos produtores ao se associarem a uma cooperativa além de identificar as contribuições trazidas pelo sistema cooperativo para a propriedade.

Para calcular o tamanho da amostra foi utilizado o cálculo amostral em Barbeta (1984, p. 45), utilizando-se a quantidade de associados, os quais totalizam 220.

O tamanho da amostra resultou em 69 associados, sendo que para tabulação e análise de dados, 45 questionários foram respondidos. A causa para o número de questionários respondidos ser menor que a amostra ocorreu devido a grande distância entre a sede das cooperativas e propriedades dos associados, além das atividades que os produtores desempenharam na época da coleta de dados, meses de dezembro, janeiro e fevereiro.

Foram utilizados questionários para a coleta dos dados. O questionário possui 2 perguntas abertas e 12 fechadas.

Foram realizados pré-testes com 5 associados em uma das cooperativas para avaliar o entendimento das questões. Não houve necessidade de alteração no questionário.

Para tratamento e análise dos dados foi utilizado o software estatístico Sphinx Léxical e análise de conteúdo. 


\section{RESULTADOS E DISCUSSÃO}

O estudo acerca das relações entre cooperativa e associado, torna-se relevante a medida que se pode observar os motivos que levaram o produtor a buscar essa forma de associativismo. Com esses indicadores, será possível compreender se a cooperativa atende as expectativas dos associados e qual o impacto dessa relação na pequena propriedade.

No fator idade, a média geral dos associados ficou em 41 anos e há um predomínio do gênero masculino ao se fazer a análise dos entrevistados. $\mathrm{Na}$ questão educação formal, constatou-se que a maioria está entre os que não completaram o ensino fundamental. Observa-se que se trata de produtores associados com poucos anos de estudo o que acaba refletido, de alguma forma, em suas rendas, pois mais da metade dos entrevistados afirmaram receber até três salários mínimos.

A faixa etária predominante é de 35 a 55 anos, representando $61,9 \%$ dos entrevistados. As faixas etárias estão numericamente bem distribuídas e há um número expressivo de associados que possuem menos de 28 anos, 14,3\%, o que indica uma forte presença do jovem no campo no planalto norte catarinense.

Há uma predominância do gênero masculino em relação ao feminino. $O$ associado, na grande maioria das famílias de agricultura familiar, ainda é o homem $(79,5 \%)$. Contudo, existe uma representatividade importante da mulher neste quesito $(20,5 \%)$ que não deve ser desconsiderada.

Verifica-se a baixa escolaridade dos entrevistados. 44,4\% dos associados estudaram até a $4^{\circ}$ série do ensino fundamental e apenas $2,2 \%$ iniciou um curso superior. 13, $3 \%$ conseguiram completar o ensino médio.

Mais da metade dos associados (53,3\%) tem como renda familiar um a três salários mínimos seguido da faixa entre 3 a 5 salários, com $26,7 \%$. Isso mostra que ainda os produtores de agricultura familiar possuem uma baixa renda, frente aos grandes produtores. 


\section{MOTIVAÇÕES PARA TORNAR-SE SÓCIO DE UMA COOPERATIVA}

Ao se descrever o que os produtores de agricultura familiar buscam na relação com uma cooperativa, é necessário verificar os motivos que os levaram a ingressarem em uma. O gráfico abaixo mostra essas motivações.

Figura 1 - Principais motivações para se associar à cooperativa

\begin{tabular}{|l|r|r|r|l|}
\hline \multicolumn{5}{|c|}{ Quais foram suas principais motivações para se associar à cooperativa? } \\
\hline \hline Preço & 23 & $23,2 \%$ \\
\hline Poder de Compra & 12 & $12,1 \%$ \\
\hline Assistência Técnica & 18 & $18,2 \%$ \\
\hline Comercialização da sua produção & 26 & $26,3 \%$ \\
\hline Armazenagem & 1 & $1,0 \%$ \\
\hline Influência de pais/parentes/outros & 3 & $3,0 \%$ \\
\hline Segurança & 12 & $12,1 \%$ \\
\hline Outros & 4 & $4,0 \%$ \\
\hline Total & 99 & $100,0 \%$ \\
\hline
\end{tabular}

Observa-se que a comercialização da produção é o principal motivo que levou o produtor a se associar a uma cooperativa, pois $26,3 \%$ dos entrevistados citaram esse fator. O preço foi o segundo item mais citado, com 23,2\%. A cooperativa, para grande parte dos associados, é uma intermediação segura para ter sua produção vendida por um preço melhor se comparado à venda individual. A assistência técnica, representada como motivação para 18,2\% dos associados, pode ser interpretada como uma ferramenta para o fortalecimento da pequena propriedade, devido ao baixo nível de educação formal e técnica destes, que buscam de alguma maneira a tecnologia e recursos necessários para enfrentar o competitivo mercado agrícola.

O resultado da pesquisa mostrou que o preço foi a escolha de $87,5 \%$ dos entrevistados que possuem renda de até 1 salário mínimo ao serem questionados sobre a principal motivação para escolher essa forma de associativismo. Já para os associados que possuem renda entre 1 a 3 salários, a comercialização da sua produção foi citada por $62,5 \%$ como o principal motivo para a associação. Mesmo fator que levou $66,7 \%$ dos entrevistados com renda entre 3 a 5 salários a fazer parte de uma cooperativa de agricultura familiar, embora $41,7 \%$ e $33,3 \%$ dos associados desta mesma faixa de renda, citaram preço e assistência técnica respectivamente. 


\section{MUDANÇAS NA RENDA APÓS A ASSOCIAÇÃO}

Um dos impactos mensuráveis trazidos pela cooperativa para a propriedade e proprietário, são as mudanças na renda. Através desse fator, pode-se avaliar se houveram melhorias ou não na renda e qual a proporção. A figura a seguir demonstra os resultados:

Figura 2 - Melhora na renda após se tornar sócio de uma cooperativa

Você percebeu alguma melhora em sua renda após se tornar sócio da cooperativa?

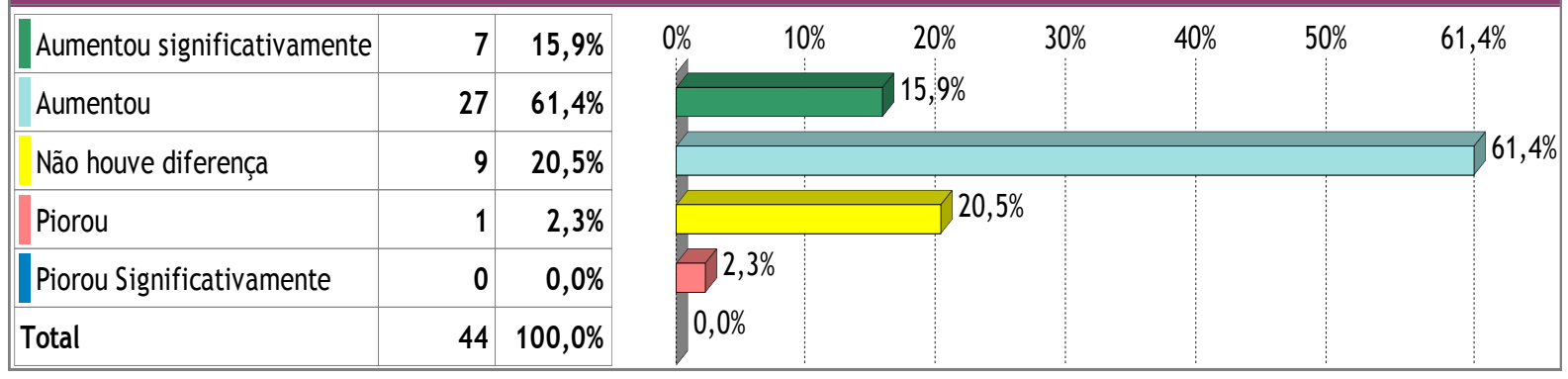

Grande parte dos associados, 61,4\%, afirmaram que sua renda aumentou após se tornar sócio de uma cooperativa. E 15,9\%, uma parcela significativa de associados, declararam que sua renda aumentou significativamente. Isso demonstra claramente que a cooperativa possui um papel fundamental neste quesito e como consequência, os produtores da agricultura familiar de certa forma vêm suas expectativas atendidas pela cooperativa.

\section{MELHORIAS NO TRABALHO DIÁRIO, AMBIENTE FAMILIAR E NECESSIDADES ATENDIDAS}

A cooperativa, além de trazer economias tangíveis para os associados como a redução dos custos por meio do poder de barganha na comercialização de insumos e a melhora do preço de venda, traz também como benefícios as economias intangíveis, ou seja, melhorias no trabalho diário e ambiente familiar do produtor como mostram as figuras 3 e 4 . 
vezes isso ocorre. Para $24,4 \%$ dos entrevistados, as necessidades são sempre atendidas pela cooperativa enquanto que $15,6 \%$ afirmaram que isso ocorre às vezes.

\section{CONSIDERAÇÕES FINAIS}

O presente estudo objetivou compreender a relação existente entre a cooperativa e seu associado, bem como os impactos trazidos pela associação à propriedade do cooperado.

Os resultados do estudo permitiram constatar a importância que a cooperativa de agricultura familiar possui no planalto norte catarinense, devido ao auxílio no fortalecimento da família do campo e no trabalho diário.

Evidenciou- se que a cooperativa possui um papel importante na agricultura familiar, pois para o produtor, ela é uma segurança de que sua produção será comercializada e vendida por um preço melhor se comparado à venda individual. Outro aspecto constatado, é que a cooperativa está atendendo as expectativas dos associados.

Identificou-se uma forte presença do jovem nas cooperativas, pois $14,3 \%$ possuem menos de 28 anos. Entretanto, foi observado um baixo grau de escolaridade entre os associados de todas as faixas etárias. $44,4 \%$ dos associados estudaram até a $4^{\circ}$ série do ensino fundamental e apenas $2,2 \%$ iniciou um curso superior.

Apesar dos resultados do estudo demonstraram que houve um aumento desta após o produtor se tornar sócio de uma cooperativa, grande parte dos entrevistados recebe até três salários mínimos mensais $(53,3 \%)$ seguido da faixa entre 3 a 5 salários, com $26,7 \%$.

As necessidades da pequena propriedade são atendidas na maioria das vezes segundo a opinião de $55,6 \%$ dos produtores. A cooperativa trouxe melhorias no trabalho diário para $47,7 \%$ e no ambiente familiar $(59,1 \%)$. Isto indica que a cooperativa está atuando de maneira a beneficiar seu associado.

Os motivos mais citados pelos sócios ao serem questionados sobre o quê os impulsionou a trabalharem com essa forma de associativismo, foram à comercialização da produção $(26,3 \%)$, preço $(23,2 \%)$ e assistência técnica $(18,2 \%)$. 
Desta maneira pode-se afirmar que a cooperativa é vista como uma organização que traz segurança, melhorias e oportunidades de crescimento.

Diante aos dados, conclui-se que os impactos trazidos pela cooperativa para a propriedade são as melhorias na renda, ambiente familiar, trabalho diário e a segurança de que sua produção será comercializada e vendida por um preço melhor se comparado à venda individual.

\section{REFERÊNCIAS}

ANDRADE JUNIOR, Remy Côrrea de. O programa de aquisição de alimentos da agricultura familiar (PAA) no planalto norte do estado de Santa Catarina: o caso da cooperativa agropecuária regional de pequenos produtores de Mafra (COOARPA). Disponível em: <http://apps.unochapeco.edu.br/revistas/index.php/rcc/ article/viewFile/452/282>. Acesso em: 08 mar. 2012.

BARBETA, Pedro Alberto. Estatísticas aplicadas às ciências sociais. Florianópolis: UFSC, 1984.

BRASIL. Ministério do Desenvolvimento Agrário. Evolução do Pronaf. Disponível em: <http://portal.mda.gov.br/portal/saf/programas/pronaf>. Acesso em: 01 set. 2011.

. Ministério do Desenvolvimento Social e Combate à Fome. Programa de aquisição de alimentos. Disponível em: <http://www.mds.gov.br/ segurancaalimentar/alimentoseabastecimento/paa>. Acesso em: 23 set. 2011.

BUAINAIN, Antonio M. Trajetória recente da política agrícola brasileira. Disponível em: <http://www.bibliotecadigital.unicamp.br/document/ ?code=vtls000195605>. Acesso em: 20 mar. 2012.

MARSCHALL, Clédio Roberto. Motivações para o cooperativismo na pequena propriedade. Disponível em <http://www.revistaoes.ufba.br/viewissue. $p h p$ ? id=51>. Acesso em: 20 mar. 2012.

PORTUGAL, Alberto Duque. O desafio da agricultura familiar. Disponível em: <http://www.embrapa.br/imprensa/artigos/2002/artigo.20041207.2590963189>. Acesso em 22 de set. de 2011.

SANTA CATARINA: características e potenciais. Disponível em: <http://cepa.epagri.sc.gov.br/aspectos/menu_sc.htm>. Acesso em: 20 mar. 2012.

SILVESTRO, M. L. et al. Os impasses sociais da sucessão hereditária na agricultura familiar. Florianópolis: Epagri; Brasília: NEAD/Ministério do Desenvolvimento Agrário, 2001. 
ZYLBERSZTAJN, D. Organização de cooperativas: desafios e tendências. Revista de Administração de Empresas, São Paulo, v.29, n.3, p.23-32, jul./set. 1994.

\footnotetext{
${ }^{1}$ Graduada em Administração- Habilitação em Comércio Exterior pela Universidade Estadual de Ponta Grossa (2007) e Tecnologia em Alimentos pela Universidade Federal do Paraná (2011). Especialista em Planejamento Estratégico e Gestão de Pessoas pela Universidade do Contestado (2012). Professora nos cursos de Técnico em Administração e Técnico Agrícola na rede estadual de ensino do Paraná e auxiliar administrativo na Universidade do Contestado- Mafra. E-mail: claferdiniz@gmail.com

${ }^{2}$ Mestre em Administração pela Fundação Universidade Regional de Blumenau (2010). Pós Graduanda em Tecnologias e Educação a Distância pela Universidade do Contestado (2012). Especialista em Marketing e Finanças pela Fundação Universidade do Contestado (2003). Graduada em Administração pela Universidade do Contestado - Campus Mafra (2000). Atualmente é professora titular tempo integral da Fundação Universidade do Contestado - Campus Mafra. Coordenadora dos Cursos de Tecnologia em Marketing e Tecnologia em Gestão de Recursos Humanos na modalidade a Distância. E-mail: andreia@unc.br
} 